\title{
Investigation of the effect of UV-LED exposure conditions on the production of vitamin $D$ in pig skin
}

Barnkob, Line Lundbæk; Argyraki, Aikaterini; Petersen, Paul Michael; Jakobsen, Jette

Published in:

Food Chemistry

Link to article, DOI:

10.1016/j.foodchem.2016.05.155

Publication date:

2016

Document Version

Peer reviewed version

Link back to DTU Orbit

Citation (APA):

Barnkob, L. L., Argyraki, A., Petersen, P. M., \& Jakobsen, J. (2016). Investigation of the effect of UV-LED exposure conditions on the production of vitamin D in pig skin. Food Chemistry, 212, 386-391.

https://doi.org/10.1016/j.foodchem.2016.05.155

\section{General rights}

Copyright and moral rights for the publications made accessible in the public portal are retained by the authors and/or other copyright owners and it is a condition of accessing publications that users recognise and abide by the legal requirements associated with these rights.

- Users may download and print one copy of any publication from the public portal for the purpose of private study or research.

- You may not further distribute the material or use it for any profit-making activity or commercial gain

- You may freely distribute the URL identifying the publication in the public portal 


\section{Accepted Manuscript}

Investigation of the effect of UV-LED exposure conditions on the production of vitamin D in pig skin

Line Lundbæk Barnkob, Aikaterini Argyraki, Paul Michael Petersen, Jette Jakobsen

PII: S0308-8146(16)30844-5

DOI: http://dx.doi.org/10.1016/j.foodchem.2016.05.155

Reference: FOCH 19304

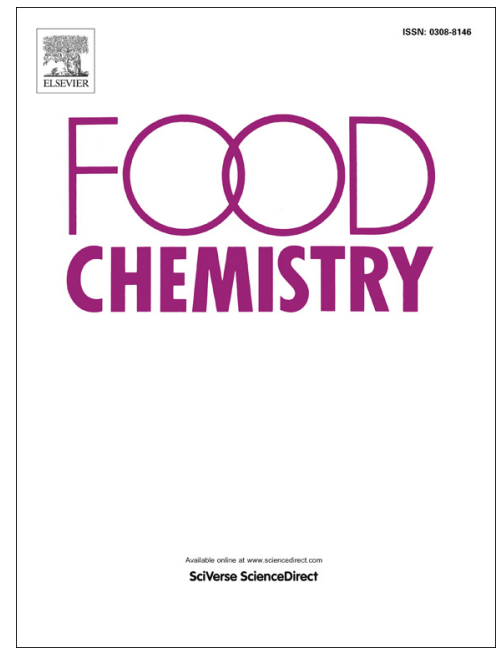

To appear in:

Food Chemistry

Received Date:

15 December 2015

Revised Date:

8 May 2016

Accepted Date:

24 May 2016

Please cite this article as: Barnkob, L.L., Argyraki, A., Petersen, P.M., Jakobsen, J., Investigation of the effect of UV-LED exposure conditions on the production of vitamin D in pig skin, Food Chemistry (2016), doi: http:// dx.doi.org/10.1016/j.foodchem.2016.05.155

This is a PDF file of an unedited manuscript that has been accepted for publication. As a service to our customers we are providing this early version of the manuscript. The manuscript will undergo copyediting, typesetting, and review of the resulting proof before it is published in its final form. Please note that during the production process errors may be discovered which could affect the content, and all legal disclaimers that apply to the journal pertain. 


\section{Investigation of the effect of UV-LED exposure conditions on the} production of vitamin D in pig skin.

Line Lundbæk Barnkoba ${ }^{a}$, Aikaterini Argyraki ${ }^{b}$, Paul Michael Petersen ${ }^{b}$ and Jette Jakobsen $^{\mathrm{a}^{*}}$

${ }^{a}$ National Food Institute, Technical University of Denmark, Denmark

${ }^{b}$ Department of Photonics Engineering, Technical University of Denmark, Denmark

* Corresponding author

E-mail address: jeja@food.dtu.dk

Keywords: Vitamin D, Bio-fortification, Light-Emitting Diodes, Ultra violet light Running title: UV-LED exposure to increase vitamin D in pig skin 


\section{ABSTRACT}

The dietary intake of vitamin $D$ is currently below the recommended intake of $10-20 \mu \mathrm{g}$ vitamin D/day. Foods with increased content of vitamin D or new products with enhanced vitamin D are warranted. Light-emitting diodes (LEDs) are a potential new resource in food production lines. In the present study the exposure conditions with ultraviolet (UV) LEDs were systematically investigated in the wavelength range $280-340 \mathrm{~nm}$ for achieving optimal vitamin D bio-fortification in pig skin. A wavelength of $296 \mathrm{~nm}$ was found to be optimal for vitamin $D_{3}$ production. The maximum dose of $20 \mathrm{~kJ} / \mathrm{m}^{2}$ produced $3.5-4 \mu \mathrm{g}$ vitamin $D_{3} / \mathrm{cm}^{2}$ pig skin. Vitamin $D_{3}$ produced was independent on the combination of time and intensity of the LED source. The increased UV exposure by UV-LEDs may be readily implemented in existing food production facilities, without major modifications to the process or processing equipment, for bio-fortifying food products containing pork skin. 


\section{Introduction}

The recommended human dietary intake of vitamin $D$ is in the range $10-20 \mu \mathrm{g} /$ day (Institute of Medicine, 2011; Nordic Nutritent Recommendations, 2014). However typical recorded dietary intakes are insufficient. Dietary supplements could be used to close the gap, however, it is not an appropriate strategy to increase intakes across the population, because uptake does not typically exceed $40 \%$. An effective food-based strategy could increase dietary intake among the population (Black, Seamans, Cashman, \& Kiely, 2012; O'Mahony, Stepien, Gibney, Nugent, \& Brennan, 2011). The optimal procedure seems to be either the fortification of a broad range of foods, or to increase the content of vitamin $D$ in foods that are already sources of vitamin D.

The natural content of vitamin $D$ in our foods varies widely. Cod liver oil contains $250 \mu \mathrm{g}$ vitamin $\mathrm{D} / 100 \mathrm{~g}$; fatty fish such as salmon, eel and mackerel contain $8-30 \mu \mathrm{g} / 100 \mathrm{~g}$, lean fish such as halibut, sole and tuna contain 3-9 $\mu \mathrm{g} / 100 \mathrm{~g}$; while meat and dairy products contain less than $1 \mu \mathrm{g} / 100 \mathrm{~g}$ (Saxholt et al., 2008). However, due to the high dietary intake of the latter food products, the contribution of vitamin D from meat and dairy products is essential, especially in populations with limited availability of fortified food (Pedersen et al., 2015).

Fortification by adding vitamin $\mathrm{D}$ to the final product (e.g. milk, margarine and bread) has been introduced in some countries. However, another strategy is bio-fortification by adding more vitamin $D$ to the feed of production animals. However, there are maximum limits for the addition of vitamin $D$ in feed in Europe $(E E C, 2004)$ which reduce the potential advantage of bio-fortifying through feed. In Denmark, the feed for laying hens contains the maximum allowed dose, $3000 \mathrm{IU}$ vitamin D/kg feed. For pigs, there is potential to approximately double the vitamin $\mathrm{D}$ content in the meat as the current recommendation of 
$800 \mathrm{IU}$ vitamin D/kg feed is below the maximum allowed $2000 \mathrm{IU}$ vitamin D/kg (Burild, Lauridsen, Faqir, Sommmer, \& Jakobsen, 2016).

It is possible to convert 7-dehydrocholesterol (7-DHC) to vitamin $\mathrm{D}_{3}$ by exposing excised skin to ultraviolet B (UVB, 290-320 nm) light (MacLaughlin, Anderson, \& Holick, 1982; Okano, Yasumura, Mizuno, \& Kobayashi, 1978). When 7-DHC, which is located in the two outer layers of the skin (the epidermis and dermis located on top of the subcutaneous fat), is exposed to UVB light it is transformed to pre-vitamin $\mathrm{D}_{3}\left(\operatorname{pre}_{3}\right)$, which isomerises to form vitamin $D_{3}$ (Holick et al., 1980). Therefore, an alternative bio-fortification strategy is to expose animals or foodstuff, containing 7-DHC or ergosterol to UV light to increase the level of vitamin $D_{3}$ and vitamin $D_{2}$, respectively. The principle is approved for use in the production of vitamin $D_{2}$ - enriched baker's yeast in the United States (Food and Drug Administration, 2012) and in the European Union (EFSA NDA Panel, 2014). Exposure of mushrooms to UVB light has been shown to increase vitamin D content in a wavelengthdependent manner (Jasinghe \& Perera, 2006). Recent studies have shown that UVBexposure of dairy cows and pigs can enhance the content of vitamin $\mathrm{D}$ in milk and pork (Burild, Frandsen, Poulsen, \& Jakobsen, 2015; Jakobsen et al., 2015).

To use this principle in the production of food requires the construction of a light-source that can accommodate all the requirements existing in food production lines. With the emerging technology of ultraviolet light-emitting diodes (UV-LEDs) it is possible to produce energy-efficient UV light sources with a narrow and tuned UVB-spectrum, which could ensure an environmentally friendly, cost-effective production process.

Thus we aimed to study the feasibility of using UV-LEDs in the production of vitamin D enhanced pork products. We investigated how the exposure conditions, namely: 
wavelength, dose and total irradiation and exposure time, can influence vitamin $D_{3}$ production when pig skin without hair is exposed to UV light, produced by UV-LEDs.

\section{Materials and methods}

\subsection{Samples of pork skin}

Skin was removed from the back of a slaughtered mini pig which had been in the control group of one of our former studies (Burild et al., 2015). Thus had never been exposed to UV light, but stored at $-20{ }^{\circ} \mathrm{C}$ for 2 years prior to the removal of the skin. Any hair and subcutaneous fat was carefully removed from the skin. A normal ruler and a scalpel were used to cut the skin into pieces of $1 \times 1 \mathrm{~cm}$. The average weight of the samples was $0.498 \pm 0.015 \mathrm{~g}$. All samples were kept at $-20^{\circ} \mathrm{C}$ before and after exposure to UV light. Prior to exposure the samples were thawed to room temperature. After exposure the samples were kept in airtight nitrogen-flushed bags. Control-samples, i.e. skin samples which were not exposed to UV light, were included in the study. All samples before and after the experiment were kept in an UV-free environment.

\subsection{The UV-LED equipment}

Twelve UV-LEDs, emitting wavelengths in the range $280-340 \mathrm{~nm}$, were purchased from Sensor Electronic Technology, Inc (SETi, Columbia, SC, USA; TO3 package, hemispherical lens window, half angle of 20-25 degrees). An UV opaque, homemade Plexiglass (RIAS A/S, Roskilde, Denmark) box was built and used to protect the experimentalist against the UV light. The irradiation of the UV-LEDs was measured by an External Optical probe (EOP-146, Instrument Systems GmbH, Munich, Germany) and a monochromator (bandpass: $1 \mathrm{~nm}$, scan step: $1 \mathrm{~nm}$, detector: Photomultiplier). The 
spectrometer, coupled to the monochromator, was a SPECTRO 320 (D) Release 5 (Instrument Systems $\mathrm{GmbH}$ ) and operated in the wavelengths between $200 \mathrm{~nm}$ and 900 $\mathrm{nm}$. The spectral distribution for each of the twelve LEDs was systematically investigated in six constant current modes: $100 \mathrm{~mA}, 200 \mathrm{~mA}, 300 \mathrm{~mA}, 400 \mathrm{~mA}, 500 \mathrm{~mA}$ and $600 \mathrm{~mA}$. The measurements were performed with contact between the detector and the light source, and afterwards a correction was introduced for the distance introduced between the sample and light source. The relation between total irradiation and distance was measured and is displayed in Figure 1. Gaussian curves were fitted to the six spectral distributions obtained for each of the LEDs. Based on the Gaussian fit the central wavelength, standard deviation and full width half maximum (FWHM) were estimated. The range was determined as plus/minus three standard deviations. Total irradiation was calculated by taking the integral of irradiations of all emitted wavelengths for each LED. The estimated values are displayed in Table 1.

\subsection{Experimental design}

All provided values are given as mean \pm standard deviation (sd).

The objective was to determine how wavelength, dose and total irradiation influence vitamin $D_{3}$ production when pig skin is exposed to UV. In all exposures, the distance between the LED's and the sample of pig skin $\left(1 \mathrm{~cm}^{2}\right)$ was kept constant at $1.5 \pm 0.1 \mathrm{~cm}$. All exposures were repeated on two samples of pig skin $(n=2)$. Pictures of the setup and the exact settings used for the LEDs in each experiment can be found in the supplementary online material (SOM, Section S1, Figure S1).

\subsubsection{Effect of wavelength on the production of vitamin $D_{3}$ in pig skin}


The effect of wavelength on the production of vitamin $D_{3}$ was tested at two different doses; namely $300 \pm 3 \mathrm{~J} / \mathrm{m}^{2}$ and $7,000 \pm 3 \mathrm{~J} / \mathrm{m}^{2}$. The total irradiation emitted at these wavelengths varied between $8.2-12.4 \mathrm{~W} / \mathrm{m}^{2}$ and $2-23 \mathrm{~W} / \mathrm{m}^{2}$, respectively. The corresponding range in exposure time was $24-37 \mathrm{sec}$ and $304-3,500 \mathrm{sec}$, respectively. The precision of the exposure time was estimated to $\pm 0.5 \mathrm{sec}$ to cover the experimentalist's response time to the timer. The LEDs were operated in constant current mode in the region between 100$600 \mathrm{~mA}$ (see SOM, Section S2, Table S1).

\subsubsection{Effect of dose on the production of vitamin $D_{3}$ in pig skin}

The LED, with a central wavelength of $296 \mathrm{~nm}$, was used to determine the effect of 6 doses on the vitamin $D_{3}$ production in pig skin. The delivered doses were $207 \mathrm{~J} / \mathrm{m}^{2}, 1,008$ $\mathrm{J} / \mathrm{m}^{2}, 2001 \mathrm{~J} / \mathrm{m}^{2}, 6,002 \mathrm{~J} / \mathrm{m}^{2}, 10,004 \mathrm{~J} / \mathrm{m}^{2}$ and $20,007 \mathrm{~J} / \mathrm{m}^{2}$. The exposure time was varied between 14 seconds and 22.50 minutes (see SOM, Section S2, Table S2). The LED was operated at a constant current of $600 \mathrm{~mA}$ and the total irradiation emitted was $14.8 \mathrm{~W} / \mathrm{m}^{2}$.

\subsubsection{Effect of total irradiation and exposure time on the production of vitamin $D_{3}$ in pig} skin

The total irradiation emitted by the LEDs was varied between $0.1-43 \mathrm{~W} / \mathrm{m}^{2}$ by adjusting the operation current at the interval from 8 to $600 \mathrm{~mA}$. The test was performed at three different central wavelengths: $292 \mathrm{~nm}, 296 \mathrm{~nm}$, and $300 \mathrm{~nm}$ and delivered a constant dose of $300 \pm 2 \mathrm{~J} / \mathrm{m}^{2}$ (see SOM, Section S2, Table S3).

\subsection{Analysis of vitamin $D_{3}$ and 7-DHC}

\subsubsection{Chemicals}

The standards used were vitamin $D_{3}$ and vitamin $D_{2}$ from Sigma-Aldrich (Denmark A/S, 
Copenhagen, DK), and 7-DHC from Cayman Chemical (Ann Arbor, MI, USA).

Concentrations of the standard solutions were determined spectrophotometrically, based on the molar absorption coefficient at $265 \mathrm{~nm}$ for vitamin $D_{3}$ and $D_{2}$ assessed as 18,300 $\mathrm{M}^{-1} \mathrm{~cm}^{-1}$ and 19,400 $\mathrm{M}^{-1} \mathrm{~cm}^{-1}$, respectively (Norman, 1979) and for 7-DHC at $281 \mathrm{~nm}$ : $11,959 \mathrm{M}^{-1} \mathrm{~cm}^{-1}$. The value for 7-DHC was obtained from the designated vitamin $\mathrm{D}_{2}$ equivalent, ergosterol (Sternberg, Stillo, \& Schwendeman, 1960).

\subsubsection{Procedure}

The content of vitamin $\mathrm{D}_{3}$ and 7-DHC were quantified by combining two methods formerly used for the quantification of vitamin D in meat and mushrooms (Burild, Frandsen, Poulsen, \& Jakobsen, 2014; Kristensen, Rosenqvist, \& Jakobsen, 2012). In short, the skin samples of $1 \mathrm{~cm}^{2}$ were thawed prior to analysis, and vitamin $D_{2}$ was added. The samples were extracted by alkaline saponification overnight at room temperature and cleaned up using liquid-liquid-extraction followed by silica solid-phase-extraction (Burild et al., 2014), followed by normal-phase preparative HPLC (Kristensen et al., 2012). Vitamin $D_{2}$ and vitamin $D_{3}$ had a retention time of $7.6 \mathrm{~min}$, and the fraction in the interval 6.8-8.5 min was collected for all samples. The 7-DHC fraction with the retention time of 10 min was collected in fractions 9.2-10.6, but only in the unexposed pig skin. Following evaporation and dissolution in the mobile phase (acetonitrile:methanol, 80:20), an isocratic separation of vitamin $\mathrm{D}_{2}$ and vitamin $\mathrm{D}_{3}$ was performed on two $\mathrm{C} 18$ columns (VYDAC $\AA$ 201TP, $5 \mu \mathrm{m}$, 250x4.6 mm, Separation Group, Inc., Hesperia, CA, USA); whereas the fraction of 7-DHC

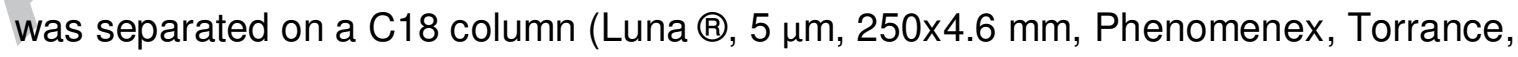
CA, USA). A photo-diode array detector (220-320 nm) was used for detection, and quantification at $265 \mathrm{~nm}$ for vitamin $\mathrm{D}_{2}$ and vitamin $\mathrm{D}_{3}$, and $281 \mathrm{~nm}$ for 7-DHC. Vitamin $\mathrm{D}_{2}$ was used as internal standard for vitamin $\mathrm{D}_{3}$, whereas $7-\mathrm{DHC}$ was quantified by use of the 
external standard. The recovery of vitamin $D_{3}$ and 7 -DHC were $>90 \%$. For vitamin $D_{3}$, the limit of quantification (LOQ) was $0.003 \mu \mathrm{g} / \mathrm{cm}^{2}$ pig skin (equals $0.6 \mu \mathrm{g} / 100 \mathrm{~g}$ pig skin), and an internal reproducibility at $5.5 \%$ in a house reference materials of salmon analysed in each series $(n=8)$. The analyses were performed in a laboratory accredited according to ISO17025 (ISO, 2005).

\section{Results and discussion}

\subsection{Production of vitamin $D_{3}$ as a function of wavelength}

The content of vitamin $D_{3}$ in the pig skin after a UV dose of $300 \mathrm{~J} / \mathrm{m}^{2}$ and $7,000 \mathrm{~J} / \mathrm{m}^{2}$ was delivered, is displayed in Figure 2 as a function of wavelength. The curves for both doses have a similar shape, with a maximum at $296 \mathrm{~nm}$, but differing in the maximum vitamin $D_{3}$ content. Negligible amounts of vitamin D3 were produced at $318 \mathrm{~nm}$, while no vitamin $\mathrm{D}_{3}$ production was observed at or above $330 \mathrm{~nm}$. At these wavelengths the exposed samples did not differ in content of vitamin $D$ from the unexposed samples i.e. the vitamin $D$ content was below LOQ.

The curves of vitamin D against wavelength (usually described as mountain shaped) are also observed when human skin, rat skin, and 7-DHC and ergosterol solutions are exposed to UV light (Kobayashi \& Yasumura, 1973; MacLaughlin et al., 1982; Olds, Lucas, \& Kimlin, 2010; Takada, Okano, Tamura, Matsui, \& Kobayashi, 1979). Estimation of optimal wavelengths has been assessed under a range of test conditions which have been summarised in Table 2.

All results, no matter the method, assess the optimal wavelength to be in the range 295$303 \mathrm{~nm}$. Furthermore, the production is very low or non-existing above $310 \mathrm{~nm}$. All this is 
in accordance with our findings. The novelty in our study is that we used UV-LEDs to create narrowband UV light, whereas all others have used traditional UV-sources coupled to either monochromators or filters.

\subsection{Production of vitamin $D_{3}$ as a function of dose}

At the optimum wavelength, $296 \mathrm{~nm}$, the content of vitamin $D_{3}$ was determined at six different doses, and is displayed in Figure 3. The best fitted curve was a logarithmic curve $(y=0.6302 L N(x)-2.9049)$ showing a correlation coefficient $\left(R^{2}\right)$ at 0.86 .

In human skin, the outer part of epidermis contains a limited amount of 7-DHC, which is mainly present in the deepest layer of epidermis (stratum spinosum and stratum basale), although the deeper layer, the dermis, has also been shown to contain 7-DHC (Holick, 1981). In this study the epidermis and dermis were both exposed, as only the subcutaneous fat was removed. From the logarithmic fit it is estimated that the maximum possible production of vitamin $\mathrm{D}_{3}$ has not been reached, and higher doses would give a higher content of vitamin $\mathrm{D}_{3}$ in the pig skin. The content of 7-DHC in unexposed skin samples was determined to be $79 \pm 6 \mu \mathrm{g} / \mathrm{cm}^{2}(\mathrm{n}=3)$. The highest obtained content of vitamin $D_{3}$ in the pig skin was between $3.5-4 \mu \mathrm{g} / \mathrm{cm}^{2}$, which was approx. $4 \%$ of the $7-\mathrm{DHC}$ content in unexposed skin. Others have used higher doses of UVB at the same wavelength. MacLaughlin et al. (1982) exposed surgically obtained human skin to different doses of UV in the interval $10,000-300,000 \mathrm{~J} / \mathrm{m}^{2}$ using a wavelength of $295 \mathrm{~nm}$. The results also seem to follow a logarithmic curve where the maximum was not reached even though the highest dose used was $300,000 \mathrm{~J} / \mathrm{m}^{2}$. At this point approx. $70 \%$ of the initial 7-DHC had been converted to pre $_{3}$ (MacLaughlin et al., 1982). Furthermore, Takada et al. (1979) exposed rat skin with doses of $1530 \mathrm{~J} / \mathrm{m}^{2}, 3,060 \mathrm{~J} / \mathrm{m}^{2}, 6,120 \mathrm{~J} / \mathrm{m}^{2}, 9,180 \mathrm{~J} / \mathrm{m}^{2}$ and 12,240 
$\mathrm{J} / \mathrm{m}^{2}$ (using a UV lamp, 280-310 nm). The amount of vitamin $\mathrm{D}_{3}$ increased linearly with doses. Two studies have reported the results of exposure of in vitro human skin models to different doses of UV in the interval $0-4,500 \mathrm{~J} / \mathrm{m}^{2}$ using a wavelength of $300 \mathrm{~nm}$. In the first case the vitamin $D_{3}$ content increased linearly with doses (Lehmann, Genehr, Knuschke, Pietzsch, \& Meurer, 2001), but in the second case the content increased linearly with the dose up to $3,000 \mathrm{~J} / \mathrm{m}^{2}$, where it reached a plateau, and stayed constant up to $4,500 \mathrm{~J} / \mathrm{m}^{2}$, thereby also following a logarithmic pattern (Lehmann, Knuschke, \& Meurer, 2007). In general there is agreement that a higher dose of UV will result in a higher content of vitamin $D_{3}$, and at some point a plateau will be reached thereby following a logarithmic pattern.

3.3. Production of vitamin $D_{3}$ is not influenced by total irradiation and exposure time at a constant dose

The effect of five different total irradiation levels at three different wavelengths was investigated at a constant dose, by using the inverse relationship between total irradiation and exposure time. The results for the production of vitamin $D_{3}$ are shown in Table 3. For each of the wavelengths, one-way ANOVA was performed, testing the hypothesis of no difference between the different levels of total irradiation used.

From the results it can be seen that it is possible to deliver a specific dose of UVB over a long or short time period and achieve the same level of vitamin $D_{3}$.

\subsection{Application in food production}


The maximum achieved content of vitamin $D_{3}$ was $3.5-4 \mu \mathrm{g} / \mathrm{cm}^{2}$ pig skin, and a content of vitamin $D_{3}$ in pig skin of $0.5 \mu \mathrm{g} / \mathrm{cm}^{2}$ can be achieved with UV-LEDs by exposure for seven seconds.

Vitamin $D_{3}$ in a food product containing pig skin can be tailored by adjusting the applied dose of UVB. For example, a pork loin with a content of $5 \mu \mathrm{g}$ vitamin $D_{3} / 100 \mathrm{~g}$ would only require a content of $0.15 \mu \mathrm{g} / \mathrm{cm}^{2}$ pig skin, assuming a skin surface area of $200 \mathrm{~cm}^{2}$ and a weight of $600 \mathrm{~g}$. The exposure time can be freely selected to fit into an existing production line, as the vitamin D content at a specific dose is independent of the inversely related parameters; total irradiation and exposure time.

The photo-degradation products of $\mathrm{preD}_{3}$ are tacysterol ${ }_{3}$ and lumisterol ${ }_{3}(\mathrm{MacLaughlin}$ et al., 1982). In the blood, vitamin D is transported bound to DBP (vitamin D-binding-protein) (Dueland, Blomhoff, \& Pedersen, 1990; Smith \& Goodman, 1971). Lumisterol 3 has no affinity, and tachysterol ${ }_{3}$ has a very low affinity for DBP which is why its presence in food will not influence the transport of vitamin $D_{3}$ in the circulation (Holick, 1981). According to an EFSA opinion on vitamin $D_{2}$ enriched foods, it is not necessary to include tachysterol ${ }_{2}$ in the product specifications when the content in the final food product is at or below 0.93 $\mu \mathrm{g} / 100 \mathrm{~g}$ (EFSA NDA Panel, 2014). For this reason, analysis of tachysterol 3 should be included in future studies aiming to utilise UV-exposure to produce vitamin D - enriched food products.

UV-LEDs as light sources are applicable due to their compact design and low energy consumption. Furthermore, LEDs can be implemented in industrial settings, while the traditional bulky sources of narrowband UV are only practical for laboratory use. LEDs allow spectral control of the emitted light, and can be easily integrated into electronic 
systems for automation. Safety rules and energy consumption are the first challenges that need to be addressed when installing UV-light sources in a food production facility. LED technology can provide dust- and moisture - proof solutions, as well as ensuring great mechanical stability, and a lack of toxic compounds. LEDs also produce minimal radiant heat, compared to other UVB-light sources, so unwanted surface heating is avoided (Souza, Yuk, Khoo, \& Zhou, 2015).

Moreover, LED systems have longer expected lifetimes, lower energy consumption, and lower maintenance costs than other UVB-light sources. However, up-front costs of installing an UVB-LED based lighting system are currently high. However, costs are expected to fall in the near future (Bergh, 2004), and LED performance is expected to continue to improve (Nishida, Saito, \& Kobayashi, 2001; Yam \& Hassan, 2005).

Future projects should assess the relevant dose needed to produce, e.g., pork loin, roast pork with crackling, fried pork, and pork crackling with an enhanced content of vitamin $D_{3}$.

\section{Conclusion}

The optimal wavelength for the production of vitamin $D_{3}$ in pig skin irradiated with LED-UV was determined to be $296 \mathrm{~nm}$.

At $296 \mathrm{~nm}$ the effect of dose on the production of vitamin $D_{3}$ in pig skin follows a logarithmic curve. The maximum applied dose of $20 \mathrm{~kJ} / \mathrm{m}^{2}$ resulted in a vitamin $D_{3}$ content of $3.5-4 \mu \mathrm{g} / \mathrm{cm}^{2}$. 
An increase in content of vitamin $D_{3}$ in pig skin can be obtained by a specific dose, which may either be given at low irradiation and long exposure time, or high irradiation combined with a short exposure time.

Food products containing pork skin may be enriched by LED-UVB exposure to increase the content of vitamin $D_{3}$.

\section{Acknowledgments}

The authors thank Simone Santos Faria for her huge effort in the laboratory. The Technical University of Denmark funded the project.

\section{References}

Bergh, A. (2004). Blue laser diode (LD) and light emitting diode (LED) applications. Physica Status Solidi (A) Applied Research, 201(12), $2740-2754$.

Black, L. J., Seamans, K. M., Cashman, K. D., \& Kiely, M. (2012). An updated systematic review and metaanalysis of the efficacy of vitamin D food fortification. The Journal of Nutrition, 142(6), 1102-1108.

Bunker, J., \& Harris, R. S. (1937). Precise evaluation of ultraviolet therapy in experimental rickets. New England Journal of Medicine, 216(4), 165 - 169.

Burild, A., Frandsen, H. L., Poulsen, M., \& Jakobsen, J. (2014). Quantification of physiological levels of vitamin D3 and 25-hydroxyvitamin D3 in porcine fat and liver in subgram sample sizes. Journal of Separation Science, 37(19), $2659-2663$.

Burild, A., Frandsen, H. L., Poulsen, M., \& Jakobsen, J. (2015). Tissue content of vitamin D3 and 25-hydroxy vitamin D3 in minipigs after cutaneous synthesis, supplementation and deprivation of vitamin D3. Steroids, 98, $72-79$.

Burild, A., Lauridsen, C., Faqir, N., Sommmer, H. M., \& Jakobsen, J. (2016). Vitamin D3 and 25-hydroxy vitamin D3 in pork and their relationship to the vitamin D status in pigs. Journal of Nutritional Science, $5, \mathrm{e} 3$

EEC. (2004). List of the authorised additives in feedingstuffs published in application of Article 9t (b) of Council Directive 70/524/EEC concerning additives in feedingstuffs. Official Journal of the European Union, C50/1, 1 - 144.

Dueland, S., Blomhoff, R., \& Pedersen, J. I. (1990). Uptake and degradation of vitamin D binding protein and vitamin D binding protein-actin complex in vivo in the rat. The Biochemical Journal, 267(3), $721-725$. 
EFSA NDA Panel. (2014). EFSA Panel on Dietetic Products, Nutrition and Allergies. Scientific Opinion on the safety of vitamin D-enriched UV-treated baker's yeast. EFSA Journal,12(1),3520 - 3539

Food and Drug Administration. (2012). Food additives permitted for direct addition to food for human consumption; Sec. 172.381 Vitamin D2 bakers yeast. Federal Register, 77(168), 52228-52232.

Holick, M. F. (1981). The cutaneous photosynthesis of previtamin D3: A unique photoendcrine system. Journal of Investigative Dermatology, 77(1), $51-58$.

Holick, M. F., MacLaughlin, J. A., Clark, M. B., Holic, S. A., Potts, T. J., Anderson, R. R., Black, I. H., Parrish, J. A. \& Elias, P. (1980). Photosynthesis of previtamin D3 in human skin and the physiologic consequences. Science, 210(4466), $203-205$.

Institute of Medicine. (2011). Dietary Reference Intakes for Vitamin D and Calcium. Washington DC: The National Academies Press.

ISO (2005). ISO/IEC 17025:2005. General Requirements for the Competence of Testing and Calibration Laboratories. Geneva, Schwitzerland:ISO Central Secretariat.

Jakobsen, J., Jensen, S. K., Hymøller, L., Andersen, E. W., Kaas, P 312 ., Burild, A., \& Jäpelt, R. B. (2015). Artificial ultraviolet $B$ light exposure increases vitamin $D$ levels in cow plasma and milk. Journal of Dairy Science, 98(9) $6492-6498$.

Jasinghe, V. J., \& Perera, C. O. (2006). Ultraviolet irradiation: The generator of vitamin D2 in edible mushrooms. Food Chemistry, 95(4), 638 - 643.

Knudson, A., \& Benford, F. (1938). Quantitative studies of the effectiveness of ultraviolet radiation of various wave-lengths in rickets. Journal of Biological Chemistry, 124, $287-299$.

Kobayashi, T., Hirooka, M., \& Yasumura, M. (1976). Effect of wavelength on the ultraviolet irradiation of 7dehydrocholesterol. Vitamins , 50,185- 189.

Kobayashi, T., \& Yasumura, M. (1973). Studies on the ultraviolet irradiation of provitamin D and its related compounds III. Effect of wavelength on the formation of potential vitamin D2 in the irradiation of ergosterol by monochromatic ultraviolet rays. Journal of Nutritional Science and Vitaminology, 19(2), $123-128$

Kristensen, H. L., Rosenqvist, E., \& Jakobsen, J. (2012). Increase of vitamin D2 by UV-B exposure during the growth phase of white button mushroom (Agaricus bisporus). Food \& Nutrition Research, 56(na), 1 -7 .

Lehmann, B., Genehr, T., Knuschke, P., Pietzsch, J., \& Meurer, M. (2001). UVB-induced conversion of 7dehydrocholesterol to 1 $\alpha, 25$-dihydroxyvitamin D3 in an in vitro human skin equivalent model. The Journal of Investigative Dermatology, 117(5), 1179 - 1185

Lehmann, B., Knuschke, P., \& Meurer, M. (2007). The UVB-induced synthesis of vitamin D3 and 1a,25dihydroxyvitamin D3 (calcitriol) in organotypic cultures of keratinocytes: Effectiveness of the narrowband Philips TL-01 lamp (311 nm). Journal of Steroid Biochemistry and Molecular Biology, 103(3-5), $682-685$.

MacLaughlin, J. A., Anderson, R. R., \& Holick, M. F. (1982). Spectral character of sunlight modulates photosynthesis of previtamin D3 and its photoisomers in human skin. Science, 216(4549), $1001-1003$.

Maughan, G. (1928). Ultra-violet wavelengths valuable in the cure of rickets in chickens. American Journal of Physiology, 87(2), $381-398$. 
Nishida, T., Saito, H., \& Kobayashi, N. (2001). Efficient and high-power AIGaN-based ultraviolet light-emitting diode grown on bulk GaN. Applied Physics Letters, 79(6), 711 - 712.

Nordic Nutrient Recommendation. (2014). Nordic Nutrition Recommendations 2012. Nordic Council of Ministers, 5(11):1. http://dx.doi.org/10.6027/Nord2014-002. Assessed 15.10.15.

Norman, A. (1979). Vitamin D: the calcium homeostatic steroid hormone. New York: Academic Press.

O’Mahony, L., Stepien, M., Gibney, M. J., Nugent, A. P., \& Brennan, L. (2011). The potential role of vitamin D enhanced foods in improving vitamin D status. Nutrients, 3(12), $1023-1041$.

Okano, T., Yasumura, M., Mizuno, K., \& Kobayashi, T. (1978). In vivo and in vitro conversion of 7dehydrocholesterol into vitamin D3 in rat skin by ultraviolet ray's irradiation. Journal of Nutritional Science and Vitaminology, 24(1), 47-56.

Olds, W. J., Lucas, R. M., \& Kimlin, M. G. (2010). Action Spectrum for Vitamin D Synthesis. UV Radiation and Its Effects - 2010, NIWA UV Workshop. 7-9 April 2010. NIWA Information Series No. 77. Copthorne Hotel, Queenstown, New Zealand, 106-107.

Pedersen, A., Christensen, T., Matthiesen, J., Knudsen, V. B., Rosenlund-Sørensen, 353 M., Biltoft-Jensen, A., Hinsch, H.-J., Ygil, K.Y., Kørup, K., Saxholt, E., Trolle, E., Søndergaard, A.B.\& Fagt, S. (2015). Dietary habits in Denmark 2011-2013. Main results. ISBN 978-87-93109-39. Søborg.

Saxholt, E., Christensen, A. T., Møller, A., Hartkopp, H. B., Ygil, K.H., \& Hels, O. H. (2008). Danish food composition databank, revision 7. Department of Nutrition, National Food Institute, Technical University of Denmark. http://www.foodcomp.dk/v7/fvdb_search.asp. Accessed 15.10.15.

Smith, J. E., \& Goodman, D. S. (1971). The turnover and transport of vitamin D and of a polar metabolite with the properties of 25-hydroxycholecalciferol in human plasma. The Journal of Clinical Investigation, $50(10), 2159-2167$.

Souza, C. D., Yuk, H., Khoo, G. H., \& Zhou, W. (2015). Application of light-emitting diodes in food production, postharvest preservation, and microbiological food safety. Comprehensive reviews in food science and food safety, 14, $719-740$.

Sternberg, J. C., Stillo, H. S., \& Schwendeman, R. H. (1960). Spectrophotometric analysis of multicomponent systems using least squares method in matrix form. Ergosterol irradiation system. Analytical Chemistry, 32(1), $84-90$.

Takada, K., Okano, T., Tamura, Y., Matsui, S., \& Kobayashi, T. (1979). A rapid and precise method for the determination of vitamin D3 in rat skin by high-performance liquid chromatography. Journal of Nutritional Science and Vitaminology, 25(5), $385-398$.

Yam, F. K., \& Hassan, Z. (2005). Innovative advances in LED technology. Microelectronics Journal, 36(2), $129-137$. 
Table 1. The central wavelength, full width at half maximum (FWHM)

\begin{tabular}{|c|c|c|c|}
\hline \multicolumn{2}{|c|}{ Central wavelength (nm) } & \multirow{2}{*}{$\begin{array}{c}\text { FWHM } \\
(\mathrm{nm})\end{array}$} & \multirow{2}{*}{$\begin{array}{c}\text { Range }^{a} \\
(\mathrm{~nm})\end{array}$} \\
\hline Purchased as & Measured as & & \\
\hline 280 & 281 & 11 & $266-296$ \\
\hline 285 & 285 & 11 & $270-300$ \\
\hline 290 & 292 & 10 & $280-304$ \\
\hline 295 & 296 & 9 & $284-308$ \\
\hline 300 & 300 & 10 & $288-312$ \\
\hline 305 & 306 & 11 & $291-321$ \\
\hline 310 & 310 & 10 & 298-322 \\
\hline 315 & 313 & 10 & $301-325$ \\
\hline 320 & 318 & 10 & $306-330$ \\
\hline 330 & 330 & 16 & $309-351$ \\
\hline 335 & 336 & 12 & $321-351$ \\
\hline 340 & 338 & 11 & $323-353$ \\
\hline
\end{tabular}

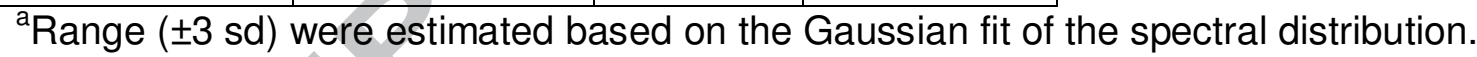


Table 2. References for investigation of optimum and no production of vitamin D. Information on sample type and full with half maximum (FWHM).

\begin{tabular}{|c|c|c|c|c|}
\hline Sample type & $\begin{array}{l}\text { Optimum } \\
\text { (nm) }\end{array}$ & $\begin{array}{c}\text { No production } \\
\text { (nm) }\end{array}$ & $\begin{array}{l}\text { FWHM } \\
(\mathrm{nm})\end{array}$ & Reference (Year) \\
\hline Rachitic chickens & 296.7 & 313 & no info & (Maughan, 1928) \\
\hline Rachitic rats & 296.7 & 313 & no info & (Bunker \& Harris, 1937) \\
\hline Rachitic rats & 280.4-302.4 & no info & no info & $\begin{array}{l}\text { (Knudson \& Benford, } \\
\text { 1938) }\end{array}$ \\
\hline Ergosterol & 295 & 340 & no info & $\begin{array}{l}\text { (Kobayashi \& } \\
\text { Yasumura, 1973) }\end{array}$ \\
\hline Rat skin & 303 & 340 & no info & (Takada et al., 1979) \\
\hline 7-dehydrocholesterol & 295 & no info & no info & $\begin{array}{l}\text { (Kobayashi, Hirooka, \& } \\
\text { Yasumura, 1976) }\end{array}$ \\
\hline Human skin & 2 & $>320$ & 3 or 5 & $\begin{array}{l}\text { (MacLaughlin et al., } \\
\text { 1982) }\end{array}$ \\
\hline In vitro human skin models & 302 & 315 & 5 & (Lehmann et al., 2001) \\
\hline In vitro human skin models & 302 & - & 5 & (Lehmann et al., 2007) \\
\hline 7-dehydrocholesterol & 295 & 315 & 1.7 & (Olds et al., 2010) \\
\hline
\end{tabular}


Table 3. The content of vitamin $D_{3}$ after exposure to a dose of $300 \mathrm{~J} / \mathrm{m}^{2}\left(295-302 \mathrm{~J} / \mathrm{m}^{2}\right)$ at 292, 296 and $300 \mathrm{~nm}$ at five different levels of total irradiation $\left(0.1-43 \mathrm{~W} / \mathrm{m}^{2}\right)$.

\begin{tabular}{|c|c|c|c|c|}
\hline $\begin{array}{c}\text { Wavelength } \\
(\mathrm{nm})\end{array}$ & $\begin{array}{c}\text { Total irradiation } \\
\left(\mathrm{W} / \mathbf{m}^{2}\right)\end{array}$ & $\begin{array}{r}\text { Vitan } \\
(\mu \mathrm{g}\end{array}$ & & $P$-value ${ }^{b}$ \\
\hline \multirow{4}{*}{292} & 0.1 & 0.57 & 0.41 & \\
\hline & 3.0 & 0.46 & 0.36 & \\
\hline & 27.2 & 0.46 & 0.45 & \\
\hline & 43.0 & 0.53 & 0.57 & \\
\hline \multirow{4}{*}{296} & 0.1 & 0.31 & 0.83 & \multirow{4}{*}{0.96} \\
\hline & 3.0 & 0.43 & 0.63 & \\
\hline & 8.4 & 0.63 & 0.61 & \\
\hline & 14.8 & 0.53 & 0.58 & \\
\hline \multirow{4}{*}{300} & 0.1 & 0.47 & 0.58 & \multirow{4}{*}{0.06} \\
\hline & 2.4 & 0.71 & 0.77 & \\
\hline & & 0.56 & 0.43 & \\
\hline & 26.8 & 0.57 & 0.52 & \\
\hline
\end{tabular}

${ }^{a}$ Each exposure was repeated twice

${ }^{\mathrm{b}} P$-values from one-way ANOVA, testing for no differences between total irradiation 
Prepared for Food Chemistry - max 6 Figures and Tables

\section{LEGENDS}

Figure 1. Relation between total irradiation percentage delivered on the sample and distance between LED and sample at a constant current of $600 \mathrm{~mA}$.

Figure 2. Content of vitamin $D_{3}$ in pig skin as function of wavelength after a delivered dose of a) $300 \mathrm{~J} / \mathrm{m}^{2}(281-310 \mathrm{~nm})$ and b) $7,000 \mathrm{~J} / \mathrm{m}^{2}(281-336 \mathrm{~nm})$.

Figure 3. Production of vitamin $D_{3}$ in pig skin at different delivered doses of UVB at $296 \mathrm{~nm}$. 


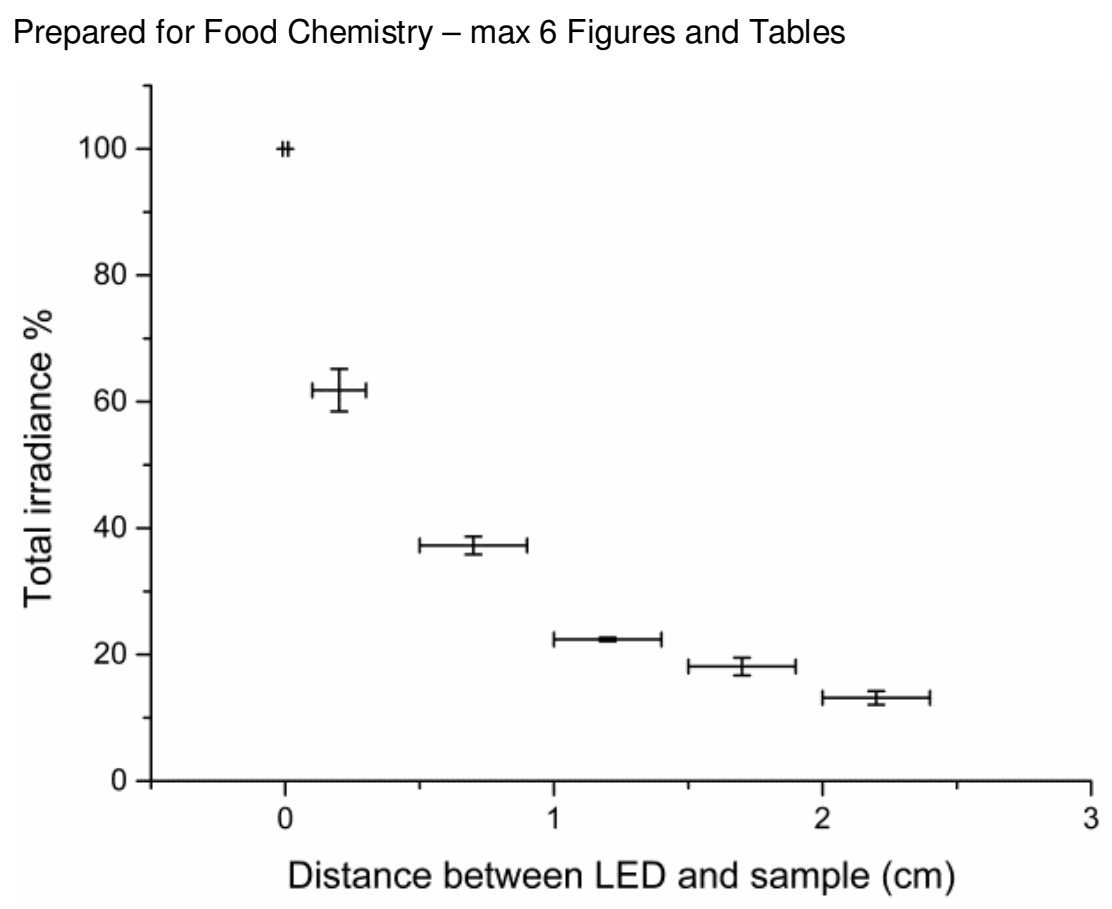

Figure 1. Relation between total irradiation percentage delivered on the sample and distance between LED and sample at a constant current of $600 \mathrm{~mA}$. 
Prepared for Food Chemistry - max 6 Figures and Tables

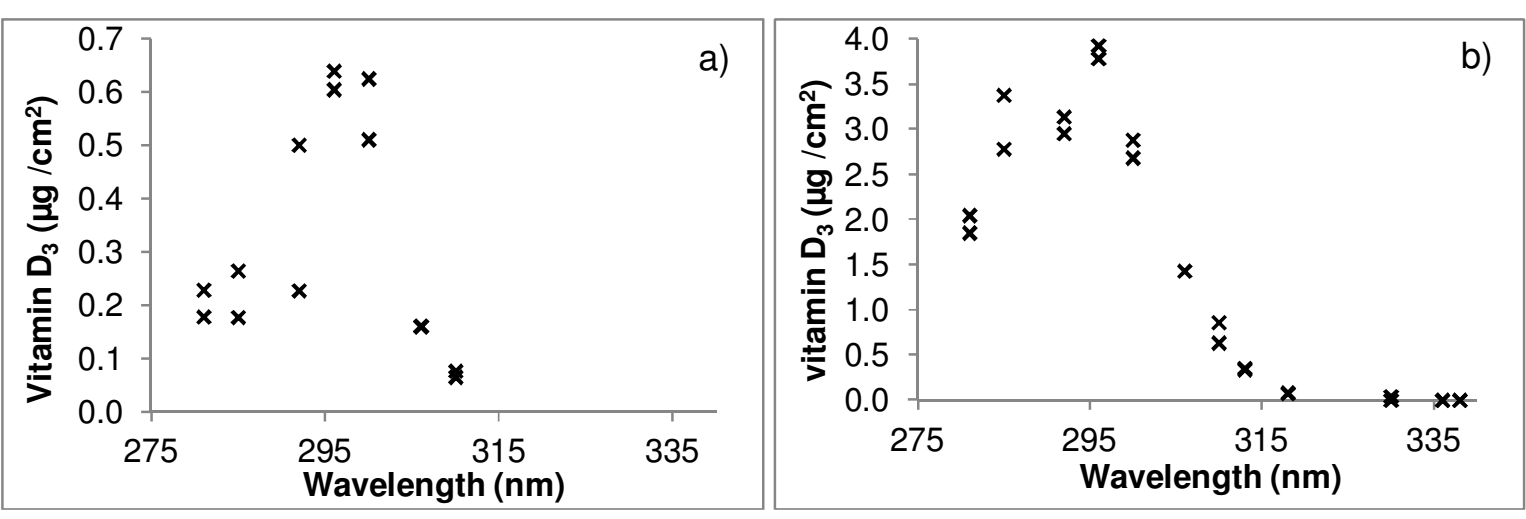

Figure 2. Content of vitamin $D_{3}$ in pig skin as function of wavelength after a delivered dose of a) $300 \mathrm{~J} / \mathrm{m}^{2}(281-310 \mathrm{~nm})$ and b) $7,000 \mathrm{~J} / \mathrm{m}^{2}$ (281-336 nm). 
Prepared for Food Chemistry - max 6 Figures and Tables

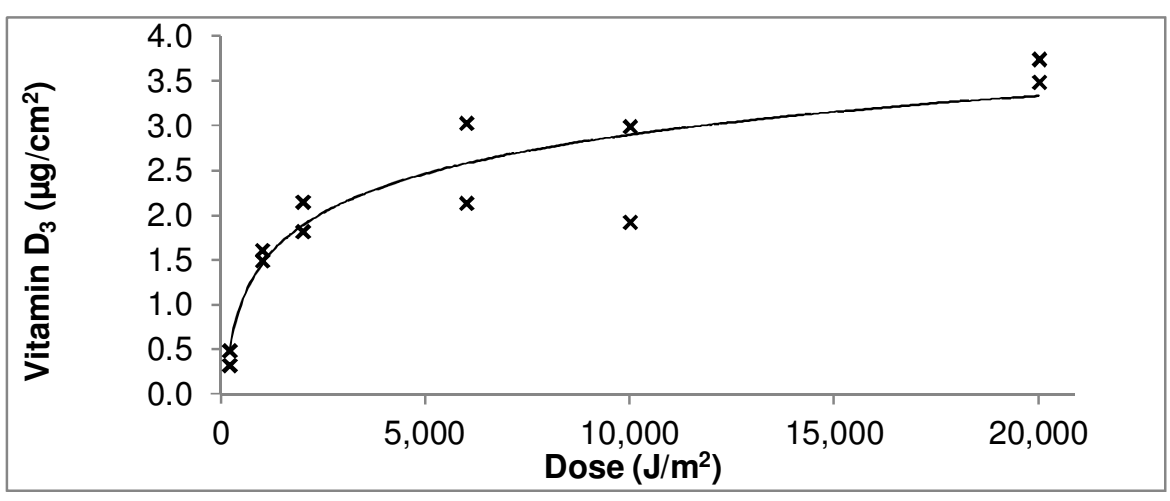

Figure 3. Production of vitamin $D_{3}$ in pig skin at different delivered doses of UVB at $296 \mathrm{~nm}$. 


\section{Highlights}

- Light-emitting diodes for production of vitamin D

- Vitamin D production dependent on dose of exposure

- Vitamin D bio-fortified pork products 